\title{
COMMUNICATION STRATEGIES IN THE CONVERSATIONS BETWEEN \\ INDONESIAN UNIVERSITY STUDENTS \\ AND A NATIVE SPEAKER
}

Farid Noor Romadlon

Universitas Muria Kudus

\begin{abstract}
Practicing conversations or dialogues in various context or situation is as the essential aspect for students because it smoothen their skill in communication and their English mastery. Whenever people use language to interact, one of the things people are doing with it is establishing a relationship between them; between the speaker speaking now and the person who will probably speak next. It means, strategies in communicating put an important role to reach the goal of the interaction or the communication.

This study is to identify the communication strategies of Indonesian university students, especially students of the English Department Education Faculty of Muria Kudus University and native speaker used in communication in natural conversation and to find out the possible factors cause the choice of the strategies in the conversation.
\end{abstract}

The method applied in this study is descriptive qualitative. The subjects of this study are fourth semester students of English Department of Muria Kudus University and one native speaker. The data were obtained by inviting and asking the students and the native speaker to have a conversation for around one hour. Then, the conversation was recorded by using camera. The recorded data were transferred into the printed one as a script. The data analysis was conducted in several ways, among other transcribing the recorded 
data, identifying each utterance and displaying the result in the table, classifying the utterances based on the type of strategies, and interpreting the communication or the conversation.

The results showed that there were 306 turns in the conversation between the students and the native speaker. The types of strategies used in the conversations were Circumlocution (C) for $38.98 \%$ (23), followed by Language Switch (LS) for $15.3 \%$ (9) and Topic Avoidance (TA) for $14.6 \%$ (8), Literal Translation (LT) for $6.8 \%$ (4), Mime (M) for $8.5 \%$ (5), Word Coinage (WC) and Message Abandonment (MA) for $6.8 \%$ (4), Appeal for Assistance (AA) for $5.6 \%$ (3), and Approximation (A) for $3.39 \%$ (2). The last finding showed that there were two main factors that cause the choice of the strategies in the conversations. They were proficiency of the speaker and features of the communicative situation.

In the use of communication strategies, both students of English Department Muria Kudus University and the native speaker try to have a relative balance of power relation without the domination of one person to others. Some factors which cause the use of the strategies are lack of meaning, social use aspect, speech, voice, and fluency.

To improve students' strategies in communication, they should practice their English more, so their speaking and their strategies will be improved. Besides, lecturers also should apply the contextual teaching in which the environment and culture are inserted into the topic.

Keyword: communication Strategies, conversation, students, native speaker 


\section{Introduction}

For most people, the main goal of learning a foreign language is to be able to communicate in the real world. It is through communication that people send and receive messages effectively and negotiate meaning (Rubin and Thompson as cited in Zhang: 2007). Nowadays, how to communicate effectively in foreign language learning becomes much more important than reading and writing. As the result, communication strategies have turned into a crucial topic for all foreign language learners and teachers, especially English.

Communication is an important point since people become language learners, especially English. They have to learn English not only from the structure or grammar, but people must know and understand how to use the language as well. This is related to the culture of the language (English). Therefore, by mastering English from both, structure and the use of it, there will be no gap in communication because the way in conveying the message is acceptable for both, speaker and hearer. The materials about expressions, utterances, and delivering ideas in communication, some have been given in semester I - II in some subjects, especially Speaking, so it is a good chance for students to practice what they have got in the real context or situation. That is why, the writer chooses fourth semester students in conducting the research. Formerly, students practice the conversation or dialogue in role play with their classmates. Practicing conversations or dialogues in various context or situation is as the essential aspect for students because it smoothen their skill in communication and their English mastery.

Whenever people use language to interact, one of the things people are doing with it is establishing a relationship between them; between the speaker speaking now and the person who will probably speak next. It means that strategies in communicating puts an important role to reach the goal of the interaction or the communication. Since communication strategies is one of important key issues of research in Second Language Acquisition (Patricia: 1994), as an English lecturer in English Department of Education Faculty, Muria Kudus University, the writer would like to investigate how 
they use English as a means of communication in natural conversation. What communication strategies they use in doing conversation or the dialogue.

\section{Background Literature}

\section{Communicative Competence}

Putting language in the perspective of communication means viewing language as a means of getting along with others, that is, to make one a part of a society. This is one valid way of looking at language. Within this tradition, the combination of knowledge and skills that enables someone to communicate in language is called communicative competence. The term Communicative Competence (CC) was coined by Hymes (1979) and since then several models of CC have arrived in the international literature including models proposed by Canale and Swain (1980), Canale (1983), CelceMurcia and others according to their research purposes (Munby, 1978 in Nasir, 2009:35).

The concept 'communicative competence' covers four main aspects: grammatical competence traditionally dealing with syntax; sociolinguistic competence dealing with social appropriateness of communication; discourse competence dealing with cohesive and coherence in discourse; and strategic competence focusing on pragmatic function of communication (Thao: 2005). Those aspects of communicative competence have received great attention in language and literacy education, particularly in second language learning.

In order to complete the theoretical framework, furthermore, the writer would like to refer to a model of communicative competence proposed by Celce-Murcia et. al. (1995:10). In detail, the following model consists of five components and it will be described as follows:

1. Discourse Competence

Discourse competence concerns with the mastery of how to combine grammatical forms covering the selection, sequencing, arrangement of words, structure, snetences, and utterances to achieve a unified spoken or written text. In addition, this 
competence covers some sub areas: cohesion, deixis, coherence, generic structure, and conversational structure.

2. Linguistic Competence

The second competence that refers to the mastery of language code (verbal or non-verbal) covers the feature and rules of language such as vocabulary, word formation, pronunciation, spelling, and semantics. Furthermore, syntax, morphology, lexicon, phonology, and orthography are also included in this competence.

3. Actionable Competence

This competence is known as the competence in conveying and understamding communicative intent, definitely, matching actional intent with linguistic form based on the knowledge of an invetory of verbal schemata that carry speech acts and speech acts sets. Furthermore, the knowledge of language functions to perform interpersonal exchange, information, opinions, feeling, situation, problems, future sceneries, and knowledge of speech act sets also the other components of this competence.

4. Sociocultural Competence

Briefly, the sociocultural competence is descirbed ass the speaker's knowledge of how to express messages appropriately with the complex social and cultural context of communication. This competence has some components which are involving social contextual, stylistic appropriateness, cultural, and non-verbal communication factors.

\section{Strategic Competence}

The last competence is called as strategic competence which refers to the knowledge of strategies and how to apply them. This competence consists of the masstery of both verbal and non-verbal communication strategies which is required if the process of communication breakdowns occur because of the limited condition in actual communication or because of lack of competence in the areas of communicative competence. When a speaker communi- 
cates his idea to other people, he requires the above competences; at least he should have discourse and linguistic competences which enable him to combine grammatical forms covering the selection, sequencing, and arrangement of words, structure, sentences that are understood by the addressee. Moreover, when he wants to use communicative strategies in his sentences, the above competences are absolutely required.

From the elaboration above, strategic competence covers all aspects of the assessment, planning, and execution of communicative tasks. It relates language competence or knowledge of language to the language user's knowledge structures and the features of the context in which the communication takes place.

\section{Communication Strategies}

Following Selinker, Tarone (1977) first distinguishes between strategies of language use and language-learning strategies. The former contains two subcategories; communication strategies (henceforth CS) and production strategies. She states communication strategies as "a mutual attempt two interlocutors to agree on a meaning in situations where requisite meaning structures do not seem to be shared" and production strategies as "an attempt to use one's linguistic system efficiently and clearly, with minimum of effort". The difference between these two aspects is the effort of the speaker to consider the effect of utterance on an interlocutor. In this way, communication strategies apply only to language in its interactive form, and necessary involve sociolinguistic as well as the usual linguistic and psycholinguistic considerations.

To be able to communicate, people need strategies. Communication Strategies is used in communication when we have communicative intentions that we find difficulty to express because of the gap in our linguistic repertoir. When we are able to anticipate it, we may be able to forestall by avoiding communication or modifying what we intended to say. If the problem arises when we are already engaged in speaking, we must try to find an alternative way in getting meaning across. The way of coping with the situationis what Tarone (1977) called Communication Strategies. 
Communication strategies are strategies that learners employ when their communicative competence in the language being learned (L2) is insufficient. This includes making themselves understood in the L2 and having others help them understand. Learners use communication strategies to offset any inadequacies they may have in grammatical ability and, particularly, vocabulary. Communication strategies aid learners with participating in and maintaining conversations and in improving the quality of communication. This, in turn, enables them to have increased exposure to and opportunities to use the L2, leading to more chances to test their assumptions about the L2 and to receive feedback. Without such strategies, learners are likely to avoid L2 risk-taking as well as specific conversation topics or situations.

Selinker (1972) identifies the use of CS as one of processes affecting second language acquisition. Since then, there have been many important contributions that have widened the scope of this field. One may highlight two main approaches to the study of Communication Strategies. The first can be said to have a linguistic basis and the second attempts to confer a cognitive or processing basis.

\section{Tarone's Typology of Communication Strategies}

One of the earliest typologies that assembled communication strategies in an organized fashion was that of Tarone (1977). The typologies consist of nine subjects and seven target language concepts which show the consistency with which learners adopt these strategies in communicative situations of this type.

Table 2.4 Tarone's Typology of Communication Strategies

\begin{tabular}{|c|c|c|}
\hline \multirow{2}{*}{ No } & \multicolumn{2}{|c|}{ Strategies } \\
\cline { 3 - 3 } & & Topic avoidance \\
\hline 1 & Avoidance & Message abandonment \\
\cline { 3 - 3 } 2 & \multirow{2}{*}{ Paraphrase } & Approximation \\
\cline { 3 - 3 } & & Word coinage \\
\hline 3 & Conscious transfer & Circumlocution \\
\cline { 3 - 3 } & & Linal translation \\
\hline 4 & Appeal for assistance & \\
\hline 5 & Mime & \\
\hline
\end{tabular}


E.Tarone, Conscious Communication Strategies in Interlanguage: a progress report, p. 197. In On TESOL' 77 in Bialystok (1990:39).

\section{a. Avoidance}

Learners sometimes make a deliberate decision not to speak because they expect communication problems to arise. This avoidance is a common strategy for second-language learners, causing them to remain silent when they would otherwise contribute to a conversation simply because some aspect of vocabulary or grammar is not known. Omitting salient but lexically difficult objects shown in the picture, such as mushroom or waterpipe, is interpreted as evidence of this strategy. The interpretations are especially well-grounded since each subject also provides descriptions in their native language. Content discrepancies between the two data sets pointed to cases of avoidance.

This strategy is distinguished into topic avoidance and message abandonment. For the former, specific topics or words are avoided to the best of the learner's ability. Learners, that is, manage to prevent the occurrence of topics that are certain to present difficulties. For the latter, learners are stumble into a topic that is too difficult and simply give up and go on to another. In this case, one might say that the learner should have avoided the topic altogether since no real effort is made to conquer the problem.

\section{b. Paraphrase}

Tarone (1977:198) in Bialystok (1990:40) defines paraphrase as 'the rewording of the message in an alternate, acceptable target language construction, in situation where the appropriate form or construction is not known or not yet stable'.

There are three types of paraphrase strategies. The first is approximation. It is the use of a single target language vocabulary item or structure, which the learner knows is not correct, but which shares enough semantics features in common with the desired item to satisfy the learner. It includes virtually all word substitutions that the learner knowingly employs to serve in place of the more accu- 
rate term. The substitute word can refer to the correct concept but at an inappropriate level, such as worm for silkworm. The second paraphrase strategy is word coinage; the learner makes up a new word in order to communicate a desired concept. The example is airball which refer to balloon. Clear cases of word coinage are less common than are instances of the other types of paraphrase strategies.

The last paraphrase strategy is circumlocution. It is a wordly extended process in which the learner describes the characteristics or elements of the object or action instead of using the appropriate target language structure. The example Tarone gives from her study is a subject attempting to refer to waterpipe: 'She is, uh, smoking something. I don't know what's its name. that's uh, Persian, and we use in Turkey, a lot of.' Here the learner is groping for features that may help the listener guess what the intended object might be.

1. Conscious Transfer

Conscious transfer has two manifestations. The first is in the literal translation of words or phrases, and the second in the interpersals of words from another language. The example is as a Mandarin speaker who translates the Mandarin toast and produces "He invites him to drink" (Tarone, 1977 in Bialystok, 1990: 41). Language switch is the straightforward insertion of words from another language.

2. Appeal for Assistance

It has occurred when the learner has consulted any source of authority: native speaker, the experimenter, a dictionary. The strategy is often smuggled into other more verbal efforts, however, by such prosodic features as rising intonation which implicitly elicits some assistance or validation from the listener.

3. Mime

This strategy includes all nonverbal accompaniments to communication, particularly those that serve in the place of a missing target language word. Some concepts are easy to simulate, such as the subject clapping his hands to indicate applause, but other gestures are considerably less interpretable by a listener. 


\section{Factors in the Choice of Strategies}

According to Bilaystok (1990: 48-49), one way of establishing whether or not the communication strategies are an organized set of options for language learners is to determine whether the selection of specific strategies is governed by identifiable factors. The potential factors in this regard are the proficiency of the learner, features of the communicative situation, and the nature of the task.

\section{a. Proficiency of the Speaker}

The first factor that can be used to predict the choice of a specific communication strategy is the proficiency level of the speaker. The strategies make different linguistic demands, and some are sophisticated for less advanced language learners. Tarone (1977:202) in Bilaystok (1990:48) acknowledges that personality differences among the subjects may account for these patterns, but claims as well that strategy preference and second-language proficiency level prove to be related. Most advanced learners and native speakers use the linguistic approach. It is because of they have more linguistic resources. Both intermediate and advanced learners use contextual approach equally. Meanwhile, the intermediate learners mostly use conceptual approach since it is a compensatory strategy for the lack of use of the linguistic approach. A study has been conducted by Bilaystok (1983) for this aspect. She examined the students in French and the results show that the advanced students use proportionally more L2-based strategies (word coinage, approximation, and circumlocution) than the intermediate students, who rely more on the L1-based strategies (topic avoidance, message abandonment, literal translation, language switch, mime, and appeal for assistance). But, some advanced students or learners sometimes also prefer to use the contextual approach strategies.

b. Features of the Communicative Situation

The features of the communication situation include transmission, grammar, speech, fluency, voice, meaning, social use, and conversation. All features belong to the language itself. Transmission is the method we use to communicate. There are two main ways we can use language, speaking and writing. In speaking, the transmis- 
sion system is spoken words. In writing, the transmission system is written words - on paper, in an email, texting on a mobile phone, and so on.

Grammar is the rules of language. Meanwhile, meaning is about knowing what words mean. It is also about being able to use the right words to say the things speaker want to say. For example, if someone wants to tell 'my mum that I've just seen a furry animal with four legs, whiskers on its face, a tail at its rear and sharp claws', she/he has to use the word cat. Knowing lots of words to describe things is our vocabulary. Other feature is social use. It is about how we use speech and language differently in different situations, know what to say, how to say it and when to say it. Voice is the ability to make sounds by vibrating the vocal cords. Speech is the sounds speakers make with their mouth when they are talking. People use speech sounds to make words while fmency is the smooth, easy production of speech. The last feature is conversation. This is about talking socially with other people. People have to be able to take turns. Sometimes, one may be the speaker and another person is the listener or on the other way. Speakers also have to be able to stick to a topic (such as talking about football, or cooking, or music). They should not jump around too much as this is confusing for the other they are having a conversation with.

\section{c. Elicitation Task}

The following methodological differences have been used by some linguists to produce the data upon which analyses of communication strategies have been based, and, may influence a language learner's selection of a specific communication strategy. They are picture description (Bialystok \& Frohlich, 1980; Varadhi, 1980), picture reconstruction (Bialystok, 1983), translation (Galvan \& Campbell, 1979; Varadhi, 1980), sentence completion (Blum-Kulka \& Levenston, 1983), conversation (Haastrup \& Phillipson, 1983), narration (Dechert, 1983; Raupach, 1983), instruction (Wagner, 1983), word transmission (Paribakht, 1985), and interview (Raupach, 1983) in Bialystok (1990:50). A study of Haastrup and Philipson (1983) in Bilaystok (1990:50-51) has been done and it shows that the regular 
tasks which tend to be natural produce some patterns that belong to paraphrase, borrowing, and literal translation). Meanwhile, the occasional tasks use strategies which tend to be well-arranged (circumlocution and approximation). Word coinage is rarely used by the students.

These three factors contribute the identification and the analysis of the study. The factors encourage the use of certain communication strategies based on the context of situation when the communication happens.

\section{Research Method}

This study is a descriptive, qualitative, and exploratory. It is descriptive because it describes the existing phenomena as naturally as possible in natural conversation between students of English Deaprtment, Education Faculty Muria Kudus University and a native speaker. Ary (1979:295) says that descriptive research studies are designed to obtain information concerning the current status of phenomena. It is identifying the status of any society, objects; set of condition, systems of thought, or any events recently.

The subjects of this study are three students of fourth semester of English Department Muria Kudus University who considered have better speaking than others and one native speaker. The native speaker is from Arizona, USA. She is a volunteer of exchange program and she assists the teaching process for a year from August 2010 to July 2011. The data is collected by inviting the students and the native speaker to the micro teaching room to get better quality for the record, asking students to have a conversation with the native speaker, recording the conversation by using camera, and transferring the audio-visual data into the printed one as a script.

The data of the study are analyzed by transcribing the conversation, identifying each utterance and display the result in the table, classifying the utterances based on the type of strategies, interpreting the communication or the conversation, and drawing conclusion. 


\section{Findings}

The results of the study consist of the frequency distribution of the communication strategies used by the students of English department, Muria Kudus University and the native speaker and factors that cause the choice of the strategies.

Table 4.1 The Distribution of Communication Strategies

\begin{tabular}{|c|c|c|c|}
\hline No & Communication Strategies & Frequency & Percentage \\
\hline 1 & Approximation (A) & 2 & $3.39 \%$ \\
\hline 2 & Word Coinage (WC) & - & - \\
\hline 3 & Circumlocution (C) & 23 & $38.98 \%$ \\
\hline 4 & Literal Translation (LT) & 4 & $6.8 \%$ \\
\hline 5 & Appeal for Assistance (AA) & 3 & $5.6 \%$ \\
\hline 6 & Message Abandonment (MA) & 4 & $6.8 \%$ \\
\hline 7 & Mime $(\mathrm{M})$ & 5 & $8.5 \%$ \\
\hline 8 & Topic Avoidance (TA) & 8 & $14.6 \%$ \\
\hline 9 & Language Switch (LS) & 9 & $15.3 \%$ \\
\hline \multicolumn{2}{|r|}{ Total } & 59 & \\
\hline
\end{tabular}

\section{Discussion}

Stating the data analysis, it is found that there is no significant problem in communication in natural conversation between students and native speaker. Since the conversation is set to be informal situation with no specific topic discussion, it is then lack of focus. As a result, they jump from one topic to another one to whatever they want to talk without any clear direction of talk. The topic is somehow dependent on the speaker's interests. The students limit the conversation to common topic such as personal, hobbies, interests, experiences, traditional costume, and food.

From any strategies used in conversation, the study indicates that the speakers tend to extend the words which are unfamiliar for interlocutors by describing them into longer phrases or sentences, and that strategy belongs to Circumlocution. The choice of this strategy is taken because of some factors. The first, speakers regard that this strategy as the easiest way to use since they only just explain or describe further about the word meant without thinking a new word 
which is more difficult or translate it directly into mother language since the students or the speakers have enough skill and background of knowledge. Second, for interlocutors, the result will be clearer without any repetition for the description or explanation because it uses familiar vocabularies. It is suitable with the explanation of Circumlocution strategy according to Bilaystok (1990: 41) that Circumlocution is a wordly extended process in which the learner describes the characteristics or elements of the object or action instead of using the appropriate target language structure. The example is a speaker's message is "bench", but he says longer;

$\mathrm{X} \quad$ : It is a little wooden chair to rest your legs when you're tired. It does not have back.

It is the same case in the JS' utterance:

JS : Yeah...Well, in America, there is sidewalk. It's like, there is a road. And, next to the road, there is an area that you can walk. It's like in Omah Mode. There is sidewalk. It's like, there is a road. And, next to the road, there is an area that you can walk. It's like in Omah Mode.

JS extends the word "sidewalk" in order to make understand meaning for the listeners.

The third, speakers are lack of social use aspect that is the appropriateness of the word or utterance use. It is different when speaker uses strategy in forming new words. He or she has to think the new target word/s and she or he has to describe the explanation when interlocutors start difficult to understand the new words. As the result, speakers work double to convey the concept. It is not effective.

Other strategies which are second mostly used by the speakers are Topic Avoidance and Language Switch. The lost interest on topics which are discussed makes the speakers tend to avoid the topics and try to change by the other topic discussion. The speakers need more background of knowledge of English. For example AS, he tries to change the topic about Kartini beach into Karimujawa Island since he 
is Jeparanese and he has many times visit the beach. Boredom from him occurs and he chooses to talk about the other topic. It is different case with Language Switch strategy. This strategy used because the target words are strange in his or her culture. It is the straightforward insertion of words from another language (Tarone, 1977 in Bialystok, 1990: 41). The speaker cannot find the term for the subject because she or he cannot find it in his or her country. That is why the speaker switches the language into native language (Bahasa Indonesia). She has less knowledge of target language culture or social. For example, JS says kangkung because there is no such a kind of vegetable in her country, so she directly switches the word into Bahasa Indonesia. Other examples are mie ayam, kembang kantbil, or RS' utterance below:

RS : Well, beside we're wearing Kebaya as traditional costume, we also wear Konde..., e..

RS still utters the word "konde" since she cannot find the English of it.

The conversation also uses Mime as the strategy in communication. Here, it is the third most used by the speakers. The speaker uses the strategy in the form of gesture to clarify the concept meant, so there will be no misperception between the speaker and interlocutor. Fluency and social use aspect are the factors cause the choice of this strategy. The speakers have not known yet how to express the appropriate word in such situation. That is why speakers prefer to use the easy strategy in conveying their message. It is also used as the additional strategy since the other strategy is not enough to convey the concept. For example, RS, she uses her hands by showing muscular hands pose to clarify what she meant by strong in "Kartini is a woman, strong, very strong woman. I mean here, it's not strong (showing her hands)." Other example is when RS makes of the process in making gethuk. She shows the way to grind by using her hands to clarify the utterance "It's grinded (using hands)."

The next strategy which has less number in use than Mime is Message Abandonment. The use of this strategy is rarely found 
in the conversation because speakers have enough background of knowledge. But, some topics make them use the strategy. It can be seen from RP's utterance. At the beginning she wants to explain about activities in celebrating Independence Day which filled one of them by singing the National Anthem of Indonesia, but, since she does not know the term "lagu kebangsaan" in English, so she pauses for a while and just mentions the title and sings the lyrics. Other example is when RS explains about traditional clothes wore in Kartini Day. She tries to explain Konde, but since it is hard for her then she just keep silent and not to continue that concept.

Interestingly, in this study the strategy of Appeal for Assistant only found 3 (three) utterances and they are not used by the students, but the native speaker. It indicates that students have good knowledge and are confident enough in conveying the concept without any assistant. On the other hands, three of the utterances which belong to the strategy are used by the native speaker, JS. She asks the interlocutors (students) the Indonesian of global warming, suburb, and desert since she does not know the Indonesian of those words.

The last strategy is Approximation. It is only found two utterances about this strategy. It means that, students are trying to speak with the appropriate term or expression and not forcing terms which is false or inappropriate in the conversation. The two utterances are all uttered by RS and the same word. JS as the native speaker actually has tried to fix it indirectly through her utterance after RS', but it seems that RS more comfortable to use country rather than state since it is not familiar in her culture or area.

Unfortunately there is no strategy found in the conversation about word coinage. The students prefer to use the other strategies because they are easier in the use. Word coinage needs double thinking. Speakers have to think the other new word as the substitute of the concept and they must explain the new word if the interlocutors are still hard to understand.

\section{Conclusion}

Based on the data analysis, the most dominant use of communication strategies is Circumlocution (C) for $38.98 \%$ (23), followed 
by Language Switch (LS) for $15.3 \%$ (9) and Topic Avoidance (TA) for $14.6 \%$ (8), Literal Translation (LT) for $6.8 \%$ (4), Mime (M) for $8.5 \%$ (5), Word Coinage (WC) and Message Abandonment (MA) for $6.8 \%$ (4), Appeal for Assistance (AA) for $5.6 \%$ (3), and Approximation (A) for $3.39 \%$ (2).

In the use of communication strategies, both students of English Department Muria Kudus University and the native speaker try to have a relative balance of power relation without the domination of one person to others. The study reveals that the students skillfully initiate the communication by introducing new topics of discussion and the native speaker as well. Despite the fact that no previous topics have been provided, the conversation run smoothly. The topics discussion ranges from season and weather, global warming, culture, tourism object, to traditional costume and food. The researcher finds that there are some factors cause the choice of the strategies. From the conversations, it can be seen that the most dominant strategy is circumlocution. Some factors which cause the use of this strategy are lack of meaning and social use aspect. These make the speakers prefer to produce longer utterances since they do not know the appropriate word or term to express.

\section{Suggestions}

The researcher offers some suggestions teachers or lecturers of EFL, students, and the future researches. The new paradigm in teaching EFL has been changed. Nowadays, teaching English not only involves the teaching of receptive skills, but also the teaching of productive skills in responding to the global need for English as a means of communication. Related to that paradigm, teachers or lecturers ideally should posses the macro and micro skills to reach the goal of teaching and learning process that is, making students to master the English.

To improve students' strategies in communication, they should practice their English more, so their speaking and their strategies will be improved. Besides, lecturers also should apply the contextual teaching in which the environment and culture are inserted into the topic. 


\section{REFERENCES}

Agustien, H.I.R. 1997. Communication Strategies in Sustained Casual Conversation. Thesis Ph.D. Macquire University, Sydney.

Alkaff, D. 2011. The Acquisition Of English And Communication Strategies Used By Kuta-Bali Beach Vendors When Communicating With English Speaking Foreigners. Thesis. Malang State University, Malang.

http://umlibrary.ac/thesis/CommunicationStrategies.html (accessed $07 / 10 / 11$ )

Arminen, I. \& M. Leinonen. 2006. Mobile phone call openings: tailoring answers to personalized summonse. Discourse studies, 8, 339-368.

Beare, Kenneth. 2008. Language Functions. http://esl.about.com/ b/a/042408. (accessed 01/05/11)

Bialystok, E. 1990. Communication Strategies. A Psychological Analysis of Second Language Use. Oxford: Basil Blackwell.

Carter, R. 2003. New Perspectives on Spoken English in the Classroom. London: Q.C.A. Available at: www.qca.org.uk. (accessed 12/10/10)

Celce-Murcia, Marriane and Elite Olshtain. 2000. Discourse and Context in Language Teaching (A Guide for Language Teachers). Cambridge University Press. 
Celce-Murcia, Marriane. 1995. Communicative Competence; A Pedagogically Motivated Model with Content Specification, in Journal of Applied Linguistics, California, Regent of University of California.

Cohen, L. et. al. 2007. Research Methods in Education. New York: Routledge.

Dell Hymes. 2004. Handout 3: Communicative Competence. Online at http://www.virginia.edu/ anthro/dhymes.html. (accessed 10/15/10)

Dwi, Rukmini. 2000. A Study of the Conversations between Overseas and Indonesian Employees of the 'Festo' Company. Unpublished Thesis. Semarang: Semarang State University.

Eggins, Suzanne and Slade, Diana. 1997. Analyzing Casual Conversation. Oxford: Creative Print and Design Wales.

Eggins, Suzanne. 1994. An Introduction to Systemic Functional Linguistics. London: Biddles, Ltd, Gildford and King's Lynn.

Ellis, Rodd. 1989. Understanding Second Language Acquisition. Oxford: Oxford University Press.

Gilfert, S. 1999. Dialog Performances: Developing Effective Communication Strategies for Non-English Majors in Japanese Universities. The Internet TESL Journal, Vol. V, No. 3, March 1999. (accessed 01/07/11)

Harmer, J. 2007. How to Teach English: An Introduction to Practice of English Language Teaching. Oxford. Pearson Longman Limited.

Halliday, M.A.K., \& Hasan, R. 1990. Language, Context, and Text: aspect of language in a social-semiotic perspective. Oxford 
University Press.

Halliday, M.A.K. 1994. Introduction to Functional Grammar. London: Edward Arnold.

Inge, H. 2004. The Use of Communication Strategies by Male and Female Students of Level 4 English Conversation Class At PPB Petra Christian University. Thesis. Petra Christian University, Surabaya.

Le, Taho. 2005. Communicative Strategies in Interlanguage. Onine at: http://www.aare.edu.au/05pap/le05661.pdf. (accessed $01 / 03 / 11)$

Lessard, M. 1997. Language Strategies: An Overview for L2 Teachers. The Internet TESL Journal, Vol. III, No. 12, December 1997. http://iteslj.org/Articles/Lessard-Clouston-Strategy. html (accessed 07/30/11)

Levinson, Stephen C. 1995. Pragmatics. Cambridge: Cambridge University Press.

McCarthy, M., Matthiessen \& D. Slide. 2002. Discourse Analysis. In N. Schmitt (ed). An Introduction to Applied Linguistics, 5573. London: Edward Arnold.

Mckay, M. 2009. Messages: The Communication Skills Book. Online at: http:/ /www.amazon.com/Messages-CommunicationSkills-Matthew-McKay/dp/1572245921 (accessed 08/12/11)

Mitani, H. 2005. Applying Conversation Analysis Methodology to the Analysis of Second Language Classroom; a review of current perspectives. ARECLS. E-Journal, 2, 1-20.

Nasir, M. 2009. Communication Strategies in Conversations between the Students of Lhokseumawe State Polytechnic and 
a Native Speaker-Like. Thesis. Semarang State University, Semarang.

Nunan, D. 1993. Introducing Discourse Analysis. New York: PENGUIN ENGLISH.

O’Malley, J.M \& A.U. Chamot. 1990. Learning Strategies in Second Language Acquisition. New York: Cambridge University Press.

Patricia. 1994. Communication Strategies and Topic Sequences in the Conversation Discourse of Spanish Learners of English. Online at: http://www.uv.es/ boup/PDF. (accessed $10 / 15 / 10)$

Pattee, Cyndi. 2003. Sociolinguistics. http://logos.uoregon.edu/explore/socioling. (accessed 10/20/10)

Schiffrin, Deborah. 1994. Approaches to Discourse. Cambridge: Balckwell.

Shin, J et. al. Communication Strategies in Text-Based Interaction between NNS and NNS. Korean Journal in Foreign Language. Vol. 5 Number 4 (serial no. 43), April 2007 (43 - 48)

Slade, Diana M. \& Gardner, Roderick J. Interactional Skill in Casual Conversation: Discourse Analysis and Teaching of Conversational Skills to Adult ESL. Australian Review of Applied Linguistics. Vol 8, Number 1, (June 1985) 105-120.

Slade, Diana M, and Gardner, Roderick J. 2000. Interactional Skill in Casual Conversation: Discourse Analysis and Teaching of Conversational Skills to Adult ESL. http://www.TESOLQuarterly-journal.com. Vol 34, Number 3, (autumn 2000) 105 - 120. (accessed 12/29/10) 
Stubbs, M. 1983. Discourse Analysis. Oxford: Basil Blackwell. Pp.xiv +272 .

Tarone, E. 1977. Conscious Communication Strategies in Interlanguage: A Progress Report, en Brown, H.D.; Yorio, C.A.; Crimes, R.H. (eds) On TESOL'\&\&: Teaching and Learning ESL, Washington DC: TESOL. (accessed 01/05/11)

Williams, J. 2006. Combining Communication Strategies and Vocabulary Development. The Internet TESL Journal, Vol. XII, No. 2, February 2006. http://iteslj.org/Techniques/WilliamsCommunicationStrategies.html

(accessed 01/07/11)

Yani, A. 2008. A Study on Teacher's Communication Strategies in Teaching English at SMP N 01 Batu. Thesis. Malang State University, Malang.

http://umlibrary.ac/thesis/CommunicationStrategies.html (accessed $07 / 10 / 11$ ) 